\title{
IgG monoclonal antibodies that inhibit osteoinductivity of human bone matrix-derived proteins (hBMP/NCP)
}

N. Kübler, J. Reuther, T. Kirchner, M. Pfaff, H. K. Müller-Hermelink, R. Albert, W. Sebald: IgG monoclonal antibodies that inhibit osteoinductivity of human bone matrix-derived proteins ( $h B M P / N C P$ ). Int. J. Oral Maxillofac. Surg. 1994; 23: 420-422. (C) Munksgaard, 1994

Abstract. Monoclonal hBMP/NCP (human bone morphogenetic protein and associated noncollagenous proteins) antibodies of the IgG class were produced. In vitro, 12 of $19 \mathrm{hBMP} / \mathrm{NCP}$ antibodies showed functional inhibition of hBMP/ NCP-induced chondroneogenesis in a neonatal muscle tissue assay. Inducing factors were characterized by their inhibiting antibodies with immunoblotting. Several peptide factors seem to be involved in the cascade of induced chondro- and osteogenesis.

Norbert Kübler ${ }^{1}$, Jürgen Reuther ${ }^{1}$, Thomas Kirchner', Martin Pfaff ${ }^{2}$, Hans Konrad Müller-Hermelink ${ }^{2}$, Rainer Albert ${ }^{3}$, Walter Sebald ${ }^{3}$ Departments of ${ }^{1}$ Oral and Maxillofacial Surgery; ${ }^{2}$ Pathology, and ${ }^{3}$ Physiological Chemistry (II), University of Würzburg, Würzbiurg, Germany

Key words: bone morphogenetic proteins; neutralizing antibodies; cartilage induction. Accepted for publication 1 January 1994

Thus far, seven different hBMPs (human bone morphogenetic proteins) have been isolated and expressed by recombinant DNA technology1,4. However, these factors show extensive osteoinductive properties only in combination with inactivated (partly extracted) bone matrix. In contrast, a human bone matrix-derived protein complex consisting of inductive proteins in association with noncollagenous proteins (hBMP/NCP) has been isolated. These semipurified peptide factors induce osteogenesis in vivo and chondrogenesis in vitro when administered alone ${ }^{2,3}$. Thus, this protein complex contains all factors and cofactors involved in bone induction. Unfortunately, further purification by conventional biochemical methods, such as chromatography, electrophoresis, and electrofocusing, has not been successful because highly purified protein samples lose inductive properties. An explanation for this finding might be that dif-

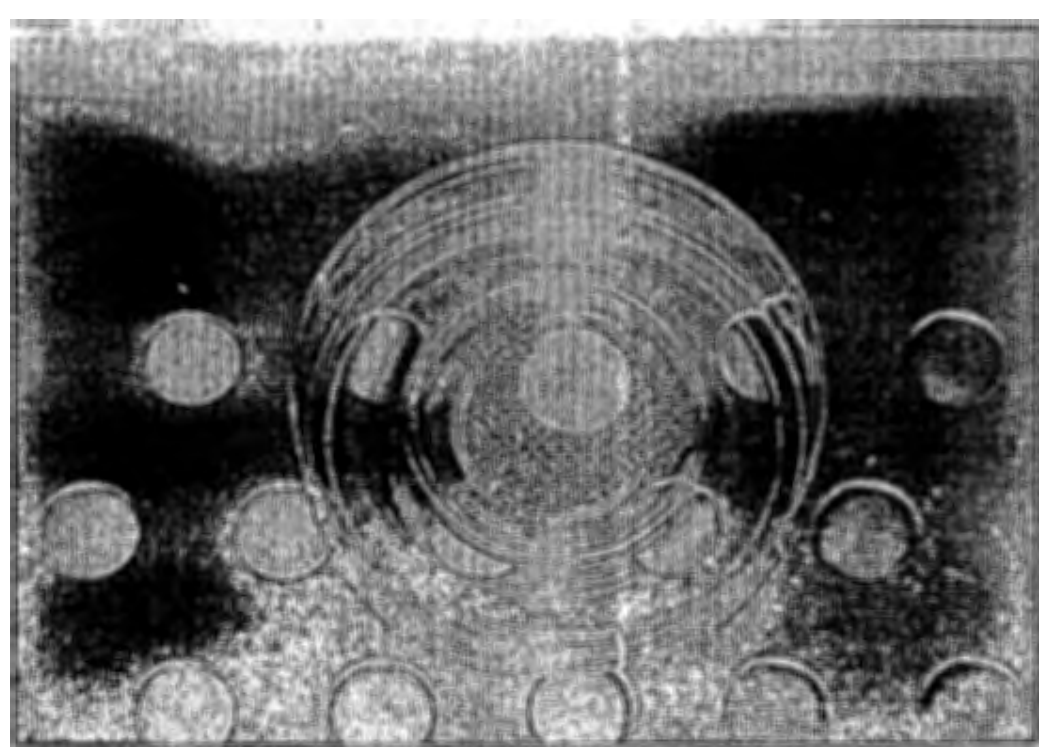

Fig. 1. Incubation of neonatal rat muscle tissue on cellulose-acetate membrane in BMP-free medium (bone matrix-free tissue assay). 


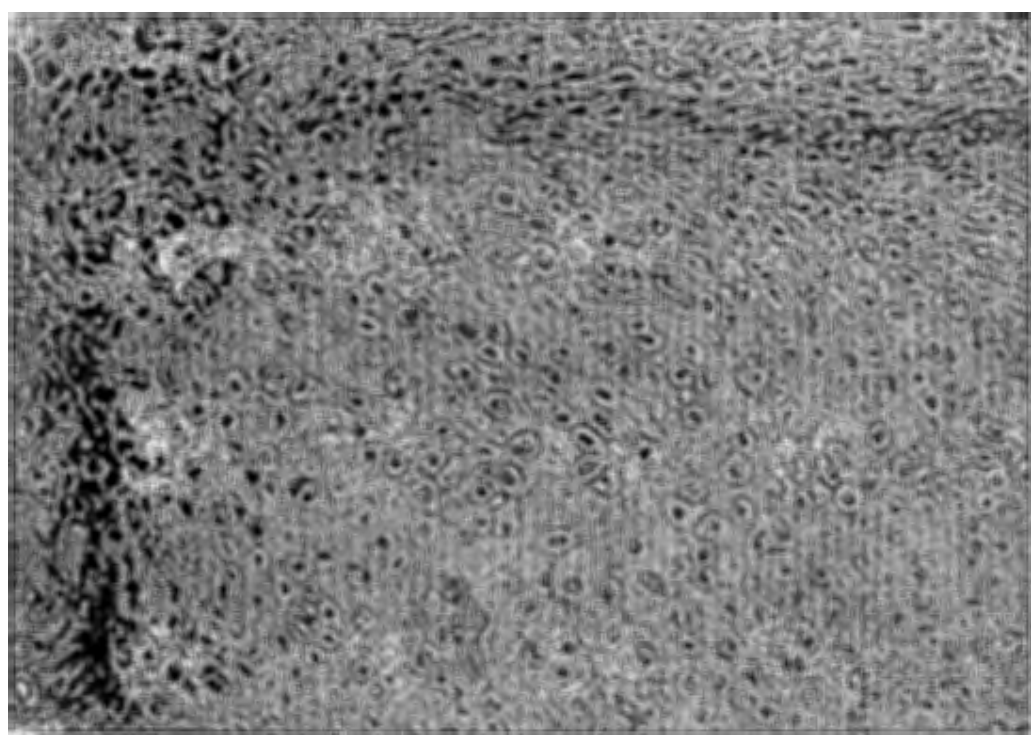

Fig. 2. Induced cartilage formation after 4-h exposure of neonatal rat muscle tissue to hBMP/ NCP, followed by incubation in BMP-free medium for 14 days $(\mathrm{HE}, \times 70)$.

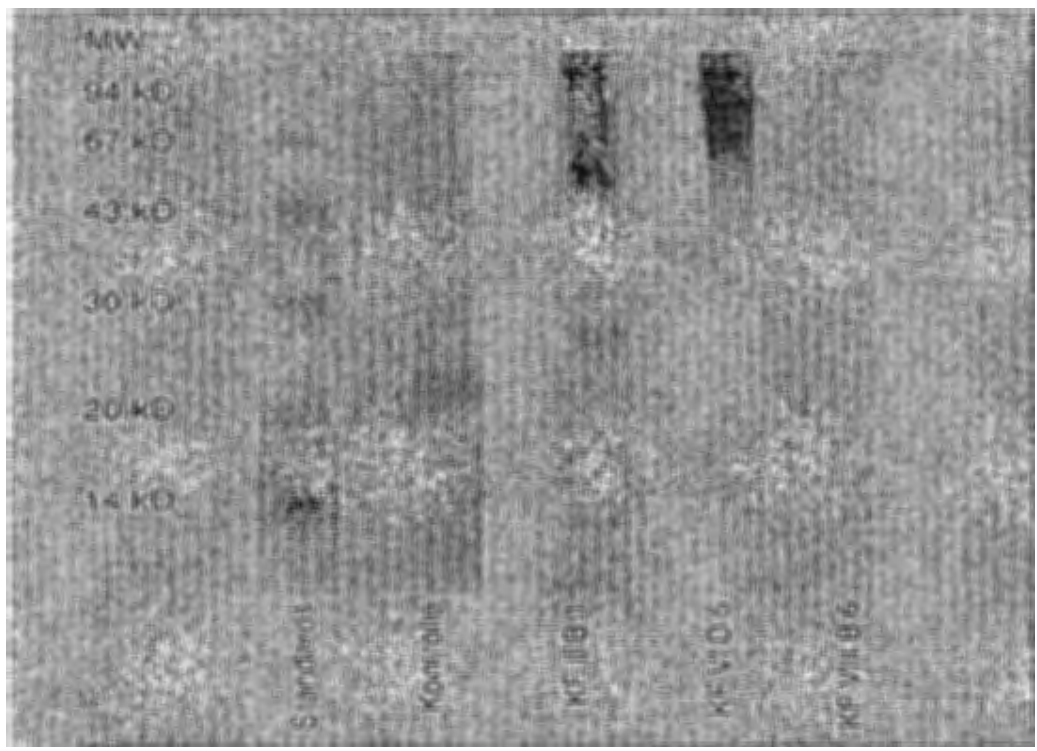

Fig. 3. Immunoblot of nonreduced hBMP/NCP with neutralizing monoclonal hBMP/NCP antibodies ((KF II B1, KF VI D5, KF VIII B6).

ferent inductive factors which are present in hBMP/NCP are involved in the cascade of induced bone formation. Only a combination of these factors might result in osteoinduction. For that reason, we decided to characterize these morphogenetic factors by functional inhibition with monoclonal antibodies.

\section{Material and methods}

Six BALB-C mice were immunized several times with hBMP/NCP. A sufficient poly-
NCP for $12 \mathrm{~h}$ in an atmosphere of $5 \% \mathrm{CO}_{2}$. Thereafter, $20 \mu$ l solution was added to 30 mg neonatal rat muscle tissue and incubated for another $4 \mathrm{~h}$ at $37^{\circ} \mathrm{C}$ in $5 \% \mathrm{CO}_{2}$. Then the tissue was transferred to cellulose-acetate membranes and incubated for 14 days in BMP-free CMRL 1066 medium at $37^{\circ} \mathrm{C}$ in $5 \% \mathrm{CO}_{2}{ }^{2}$. The control consisted of muscle tissue incubated for $4 \mathrm{~h}$ with hBMP/NCP in the absence of hBMP/NCP antibodies. Finally, the tissue samples were examined histologically for cartilage formation.

\section{Results}

Control experiments revealed that $\mathrm{hBMP} / \mathrm{NCP}$ induced cartilage in $7 / 23$ explants (Table 1). Functional inhibition of hBMP/NCP-induced chondrogenesis was observed with the monoclonal hBMP/NCP antibodies of 12 clones. The antibodies of seven clones showed no neutralizing effect (Table 1). Immunoblotting with the neutralizing antibodies showed strong reactivity with hBMP/NCP in six cases. The remaining six clones showed weak reactivity (Table 1 ).

Immunologic characterization of inhibited inductive factors by immunoblotting with the neutralizing antibodies KF II B1 and KF VIII B6 showed protein bands of nonreduced hBMP/NCP with mol. masses of 25 and $43 \mathrm{kDa}$, respectively. In contrast, the neutralizing antibody KF VI D5 reacted with proteins with mol. masses of 67 and $85 \mathrm{kDa}$ (Fig. 3).

After reduction of $h B M P / N C P$, the antibodies $\mathrm{KF}$ II $\mathrm{Bl}$ and $\mathrm{KF}$ VIII $\mathrm{B} 6$ reacted with proteins with mol. masses of $20,22,25,35$, and $50 \mathrm{kDa}$ in the immunoblot. The antibody KF VI D5 showed immunoreactivity with proteins with mol. masses of 28,50 , and $75 \mathrm{kDa}$.

Nonreduced as well as reduced hBMP/NCP showed major protein components with mol. masses of 14,22 , and $30 \mathrm{kDa}$ in the controls (Fig. 3).

clonal antibody level in blood samples was determined with the enzyme-linked immunosorbent assay. Thereafter, the animals were killed, and cell fusion between spleen cells and myeloma cells was done. Subcloning resulted in 19 clones that produced IgG antibodies which showed reactivity with hBMP/ $\mathrm{NCP}$ in the enzyme-linked immunosorbent assay, as well as in the immunoblot. The functional inhibitory properties of the antibodies were tested in a muscle tissue assay which was free of bone matrix (Figs. 1 and 2). A volume of $100 \mu \mathrm{l}$ hybridoma supernatant was preincubated with $800 \mu \mathrm{g} \mathrm{hBMP} /$

\section{Discussion}

From the present results, it seems likely that several different inductive factors which are present in bone matrix, as well as in hBMP/NCP, are involved in the cascade of induced endochondral bone formation. These factors act synergistically and their concerted action seems to be necessary to obtain a strong morphogenetic response. Further investigations are 
Table 1. Functional inhibition of hBMP/NCP-induced chondrogenesis by monoclonal hBMP/ NCP antibodies

\begin{tabular}{lcclcc}
\hline Antibody & $\begin{array}{c}\text { Chondro- } \\
\text { genesis }\end{array}$ & $\begin{array}{c}\text { Immuno- } \\
\text { blot }\end{array}$ & Antibody & $\begin{array}{c}\text { Chondro- } \\
\text { genesis }\end{array}$ & $\begin{array}{c}\text { Immuno- } \\
\text { blot }\end{array}$ \\
\hline KF II B1 & $0 / 23$ & + & KF VII Cl & $0 / 4$ & + \\
KF II A4 & $0 / 6$ & $(+)$ & KF V B3 & $1 / 4$ & $(+)$ \\
KF II B3 & $1 / 7$ & $(+)$ & KF VII C3 & $0 / 3$ & + \\
KF VI B3 & $2 / 3$ & $(+)$ & KF VIII B6 & $0 / 4$ & + \\
KF III B5 & $0 / 4$ & $(+)$ & KF V C1 & $0 / 4$ & $(+)$ \\
KF IV C2 & $1 / 4$ & $(+)$ & KF V B5 & $0 / 3$ & $(+)$ \\
KF VIII B1 & $0 / 3$ & + & KF VI A3 & $4 / 19$ & ++ \\
KF VI D5 & $0 / 4$ & + & KF VIII D1 & $0 / 4$ & $(+)$ \\
KF V D1 & $3 / 19$ & +++ & KF V A6 & $0 / 3$ & $(+)$ \\
KF VII C2 & $1 / 4$ & $(+)$ & Control & $7 / 23$ & - \\
\hline
\end{tabular}

necessary to find out whether all these factors represent morphogens or whether some of them act as cofactors and possibly represent bone matrix-derived peptide growth factors.

The finding that the respective monoclonal antibodies reacted with several protein bands in the immunoblot can be explained by partial protein degradation in the process of hBMP/NCP extraction from human bone matrix. Furthermore, there seems to be a high affinity of the inductive factors for noncollagenous proteins.
If further investigations confirm these preliminary results, the respective immunologically characterized inductive factors could be isolated by affinity chromatography, and their amino acid sequences could be determined for later molecular cloning.

Acknowledgment. This study was supported in part by the Deutsche Forschungsgemeinschaft (Ku 655/2-1, Se 435/3-1).

\section{References}

1. Celeste AJ, Iannazzi JA, Taylor RC, et al. Identification of transforming growth factor beta family members present in bone-inductive protein purified from bovine bone. Proc Natl Acad Sci U S A 1990: 87: 9843-7.

2. KÜBLER N, URIST MR. Allogenic bone and cartilage morphogenesis - rat BMP in vivo and in vitro. J Cranio-Max-Fac Surg 1991: 19: 283-8.

3. Kübler N, URist MR, Reuther J. Osteoinduktion und Knorpelbildung in vivo and in vitro durch "bone morphogenetic protein". In: Schwenzer N, Pfeiffer G, eds.: Fortschritte der Kiefer- und Gesichts-Chirurgie, Vol. 36. Stuttgart: Thieme, 1991: 230-2.

4. Wozney JM, Rosen V, Celeste AJ, et al. Novel regulators of bone formation: molecular clones and activities. Science 1988: 242: 1528-34.

Address:

Dr Dr Norbert Kübler

Klinik und Poliklinik für Mund-, Kiefer- und Gesichtschirurgie

Universität Würzburg

Pleicherwall 2

97070 Würzburg

Germany 